\title{
Modeling Sediment Transport and River Bed Evolution in River System
}

\author{
Wanshun Zhang, Yanhong Xu, Yanru Wang, and Hong Peng
}

\begin{abstract}
The problem of sedimentation has significant impacts on the operation lifetime of the reservoir. A two dimensional numerical model has been developed to simulate the transport of sediment and the evolution of the river bed in river system. The model consists of hydrodynamic equations, sedimentological equations and bed deformation equations. Water-sediment conditions and the abrupt change of water level and flow, which are influenced by gate dams, were emphatically considered in the simulation. The field measurements of erosion-sedimentation thickness of 2006, 2007, 2008 and 2009 in three sections are used for the model validation and the simulation results agree with the measurements well. The model is applied to simulate the process of sediment deposition at the upper reaches of Three Gorges Reservoir Region. The model results can reflect the detailed changes of sediment deposition thickness of river channel in the next 70 year.
\end{abstract}

Index Terms-2D mathematical model, erosion and deposition, sediment, Yangtze River.

\section{INTRODUCTION}

The movement of sediment shows profound significance to river. The process of sediment transport and deposition can change the topography of the river bed [1]. And the sediment deposition is a key factor to limit the river development and management. However, ever increasing human activities, such as extensive damming have increased sediment deposition in the river channel and reservoirs [2], [3]. Take the Three Gorges Dam (TGD) as an example, the sediment discharge of Qinxichang and Yichang stations were similar, and net erosion or deposition along the channel between Qingxichang and Yichang was little before TGD impoundment; however, after impoundment, the average trapped sediment was approximately $118 \mathrm{Mt} / \mathrm{y}$ from 2003 to 2006 [4].

During the comprehensive using and regulation of reservoir, sedimentation and erosion is the key point of reservoir life and efficiency. With the running time growth of the reservoir, the operation of the project will result siltation in the upper reaches and erosion of the downstream river bed [5]. The problem of sedimentation will have significant impacts on the operation lifetime of the reservoir, the flood control capacity and the shipping. So it is very important to research the process of sediment transport, and its

Manuscript received April 9, 2013; revised July 8, 2013.

W. S. Zhang, Y. H. Xu, and Y. R. Wang are with the School of Resource and Environmental Science, Wuhan University, Wuhan, China (e-mail: wszhang@whu.edu.cn, yhxu0515@whu.edu.cn, wangyanru2211@whu. edu.cn).

H. Peng is with the School of Water Resources and Hydropower Engineering, Wuhan University, Wuhan, China, 430072 (e-mail: hongpeng@whu.edu.cn). significance mainly shows in the following aspects: overall problem, longer-term problem and complex problem.

Over the past decades, the development of sediment transport mathematical models has been receiving more and more recognition, because they can be applied to assess the process of river bed evolution [6], [7]. On the basis of the theories of overseas and domestic experts, the theoretical and applied researches of one-dimensional (1D) models are very mature, and the reliability and accuracy are good [1], [8], [9]. The 1D model can analyze the general changes of flow and riverbed from a macroscopic view, but cannot simulate the local sediment movement in detail. Then the two-dimensional (2D) models are developed to simulate the refine local riverbed deformation and sediment deposition process in vertical and horizontal [10]-[12]. These models represent an improvement in the description of the sediment erosion and deposition in river system. However, as more and more water projects have been built, the abrupt changes of river flow-sediment conditions that influenced by the hydro-junctions are growing [13], [14]. Then there is a need for a comprehensive modeling system that can realistically describe significant sediment erosion and deposition process.

In the present study, the flow velocity, sediments discharge and bed-load gradation composition form the focus of the study, with which the transport of sediment and the thickness of erosion-sedimentation can be simulated by the developed $2 \mathrm{D}$ numerical model in river system. The model contains the hydrodynamic sub model, and the sedimentological sub model together with the bed deformation sub model. After calibration and validation, the model is applied to simulate the erosion and deposition process of sediment in the Three Gorges region. The results should provide a scientific basis for the improvement of the sediment management, which is the primary objective of the study.

\section{MATHEMATICAL MODEL}

The mechanical migration and the physical migration are the main mechanisms of sediment transport, and the transport processes are very complicated. Meanwhile, suspended and bed sediments, which are transport by the river flows, can cause bed scouring and siltation, and then lead to bed deformation. Therefore, the hydrodynamic and hydrological conditions, such as water flow velocity, bed material grade and sediment concentration, are the main factors influencing sediment transport.

\section{A. Hydrodynamic Sub Model}

The hydrodynamics sub model based on the full set of 2D Saint-Venant equations are as follows:

Continuity equation: 


$$
\frac{\partial z}{\partial t}+\frac{\partial(h+z) u}{\partial x}+\frac{\partial(h+z) v}{\partial y}=0
$$

Momentum equations:

$$
\begin{aligned}
\frac{\partial h u}{\partial t}+ & \frac{\partial}{\partial x}(h u u)+\frac{\partial}{\partial y}(h v u)+g h \frac{\partial z}{\partial x} \\
& +g \frac{n^{2} u}{(h+z)^{1 / 3}} \sqrt{u^{2}+v^{2}}=\frac{\partial}{\partial x}\left(h \gamma \frac{\partial u}{\partial x}\right)+\frac{\partial}{\partial y}\left(h \gamma \frac{\partial u}{\partial y}\right) \\
\frac{\partial h v}{\partial t}+ & \frac{\partial}{\partial x}(h u v)+\frac{\partial}{\partial y}(h v v)+g h \frac{\partial z}{\partial y} \\
+ & g \frac{n^{2} v}{(h+z)^{1 / 3}} \sqrt{u^{2}+v^{2}}=\frac{\partial}{\partial x}\left(h \gamma \frac{\partial v}{\partial x}\right)+\frac{\partial}{\partial y}\left(h \gamma \frac{\partial v}{\partial y}\right)
\end{aligned}
$$

where $u$ and $v$ are the components of the water velocity along the $x$ - and $y$-axes directions in the Cartesian coordinates $(\mathrm{m} / \mathrm{s})$, respectively; $z$ is the free surface elevation $(\mathrm{m}) ; h$ is the water depth $(\mathrm{m}) ; q_{l}$ is the discharge of lateral inflow along stream $\left(\mathrm{m}^{3} / \mathrm{s}\right) ; g$ is the acceleration of gravity $\left(\mathrm{m} / \mathrm{s}^{2}\right) ; \gamma$ is the turbulence viscosity coefficient $\left(\mathrm{m}^{2} / \mathrm{s}\right) ; n$ is the Manning coefficient of roughness.

\section{B. Sedimentological Sub Model}

The transport of suspended sediments is described by the nonequilibrium suspended sediment transport equation.

Continuity equation of suspended sediments:

$$
\begin{aligned}
& \frac{\partial s_{i}}{\partial t}+u \frac{\partial s_{i}}{\partial x}+v \frac{\partial s_{i}}{\partial y} \\
& =\varepsilon_{s}\left(\frac{\partial^{2} s_{i}}{\partial x^{2}}+\frac{\partial^{2} s_{i}}{\partial y^{2}}\right)+\alpha_{s i} \omega_{i}\left(s_{i}^{*}-s_{i}\right)
\end{aligned}
$$

where subscript $i$ indicates the $i$-th size group of suspended sediments; $s_{i}$ and $s_{i}{ }^{*}$ are the depth-averaged suspended sediment concentration, respectively $\left(\mathrm{kg} / \mathrm{m}^{3}\right) ; \quad \varepsilon_{\mathrm{s}}$ is the diffusion coefficients of sediment; $\omega_{i}$ is the setting velocity of sediment $(\mathrm{m} / \mathrm{s}) ; a$ is the recovery coefficient of suspended sediment, with $a=1.0$ for the erosion process $\left(s_{i}{ }^{*}>s_{i}\right)$ and $a=$ 0.25 for the deposition process $\left(s_{i}{ }^{*}<s_{i}\right)$.

The sediment transport capacity $s_{i}{ }^{*}$ is calculated as [15]:

$$
s_{i}^{*}=K_{s}\left(U^{3} / g h \omega_{i}\right)^{m}
$$

where $U$ is magnitude of flow velocity, $U=\sqrt{u^{2}+v^{2}} ; K_{s}$ and $m$ are empirical coefficients.

The sediment-transport rate of bed load is as follows:

$$
q_{s b}=\frac{k_{1}}{c_{0}^{2}} \frac{\rho_{s} \rho}{\rho_{s}-\rho} \frac{\left(u-u_{c}\right) \bar{u}^{3}}{g h \omega}
$$

in which $q_{s b}$ is the exchange of sediment material between bed and suspension; $\omega$ is the setting velocity of bed sediment average particle size $(\mathrm{m} / \mathrm{s}) ; \rho_{s}$ and $\rho$ are the density of sediment and water $\left(\mathrm{kg} / \mathrm{m}^{3}\right) ; u_{c}$ is the initating setting velocity of bed sediment average particle size $(\mathrm{m} / \mathrm{s}), c_{0}=h^{1 / 6} / n \sqrt{g}$.

\section{Bed deformation sub model}

The bed deformation sub model describes the process of bed deformation because of erosion and deposition by suspended sediments and bed sediments.

Bed deformation equation of suspended sediments:

$$
\rho^{\prime}{ }_{s} \frac{\partial z_{s i}}{\partial t}=\alpha_{s} \omega_{i}\left(s_{i}-s_{i}^{*}\right)
$$

Bed deformation equation of bed sediments:

$$
\rho_{b}^{\prime} \frac{\partial z_{b i}}{\partial t}+\frac{\partial q_{b x i}}{\partial x}+\frac{\partial q_{b y i}}{\partial y}=0
$$

Equation of bed material graduation:

$$
\begin{aligned}
& \rho_{s}^{\prime} \frac{\partial E_{m} P_{m i}}{\partial t}+\alpha_{s} \omega_{i}\left(s_{i}^{*}-s_{i}\right)+\frac{\partial q_{b x i}}{\partial x}+\frac{\partial q_{b y i}}{\partial y} \\
& +\left[\varepsilon_{1} P_{m i}+\left(1-\varepsilon_{1}\right) P_{m i, 0}\right] \rho^{\prime}{ }_{s}\left(\frac{\partial z}{\partial t}-\frac{\partial E_{m}}{\partial t}\right)=0
\end{aligned}
$$

where $Z_{s i}$ and $Z_{b i}$ are the thickness of sediment generated by suspended sediment and bed sediment, respectively (m); $\rho_{s}^{\prime}$ and $\rho^{\prime}{ }_{b}$ are the dry density of suspended and bed load, respectively $\left(\mathrm{kg} / \mathrm{m}^{3}\right) ; \alpha_{s}$ is the recovery saturation coefficient of suspended sediment; $P_{m i, 0}$ is the initial bed material grade; $q_{b x}$ and $q_{b y}$ are the sediment-transport rate of bed load along the $x$ - and $y$-axes directions in the Cartesian coordinates, respectively $(\mathrm{t} / \mathrm{d}) ; E_{m}$ is the depth of mixed layer $(\mathrm{m})$, when the initial bed is washed, then $\varepsilon_{l}=0$, otherwise $\varepsilon_{l}=1$.

\section{Initial and Boundary Conditions}

The initial values of flow velocity, water level, suspended sediments discharge and bed-load gradation composition are set for each grid at the start time.

Two types of boundary, open and closed boundaries, are prescribed along the boundary of the computational domain. For open boundaries, river flow, flow velocity, sediment discharge and bed-load transport rate are given at the upstream boundary; and the water level is given at the downstream boundary. For closed boundaries, flow velocity and all fluxes are set to zero to the solid boundaries.

\section{E. Numerical Discretization and Solution}

The equations are discretized in the framework of the Finite Volume Method (FVM). The upwind scheme is utilized to compute the convection items on non-orthogonal, quadrilateral grids [16]. The coupling of pressure and velocity on non-orthogonal grid arrangement is obtained by using the Semi-Implicit Method for Pressure Linked Equations (SIMPLE) algorithm and the momentum interpolation procedure [17].

\section{VALIDATION}

\section{A. Study Area}

The ongoing Three Gorges reservoir is located in the Yichang City, Hubei Province of China. As one of the largest water-power engineerings, the total storage of the Three Gorges reservoir is 39.3 billion $\mathrm{m}^{3}$, and the flood control capacity is 22.15 billion $\mathrm{m}^{3}$. The Three Gorges reservoir has put into operation in 2009. Because of the large sediment charge of the Yangtze River, the mean sediment content is $1.19 \mathrm{~kg} / \mathrm{m}^{3}$, and average annual sediment discharge is 53 million $\mathrm{kg}$. The research results of the preliminary design stage of Three Gorges Project showed that the time of reservoir sedimentation would last more than 100 year. 
Though some methods have been carried out to reduce the sediment charge, the sediment deposition is still the most important problem affect the development of reservoir's synthetic benefit in some degree. The study area is outlined in Fig. 1.

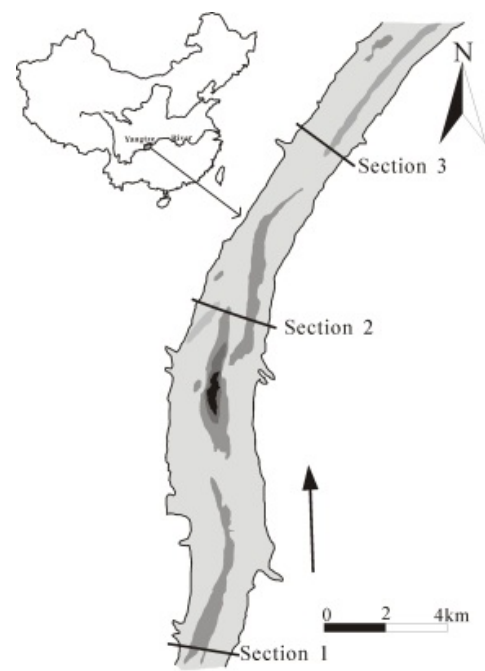

Fig. 1. Map of the study area.

\section{B. Parameters}

The inflow and downstream boundary conditions and the water and sediment data are obtained from historical hydrological measurements of the Zhutuo, Wulong and Beipei gauging station. The roughness $n$ is based on the observed water flow of the simulated reach from 2009 to 2010 within a range of $0.028-0.030$. The coefficients of suspended sediment transport of $K$ ranges from 0.9 to 1.5 and $m$ adopts 0.95 .

\section{Validation Results}

The numerical model is verified by comparing the simulation results with the field data. The topographic data on November 1, 2006, October 1, 2007, April 1, 2008, April 1, 2009 and October 1, 2009 are used for the verification. Fig. 2- Fig. 4 shows the comparison of the thickness of erosion-sedimentation between the model results and the observation at Section 1, Section 2 and Section 3, respectively. It can be seen that in general the calculated thickness of erosion-sedimentation of different years agree well with the measured data for the three sections. Therefore, the validity of the model is determined and the model can be used to forecast the sediment deposition at the upper reaches of Three Gorges Reservoir Region.

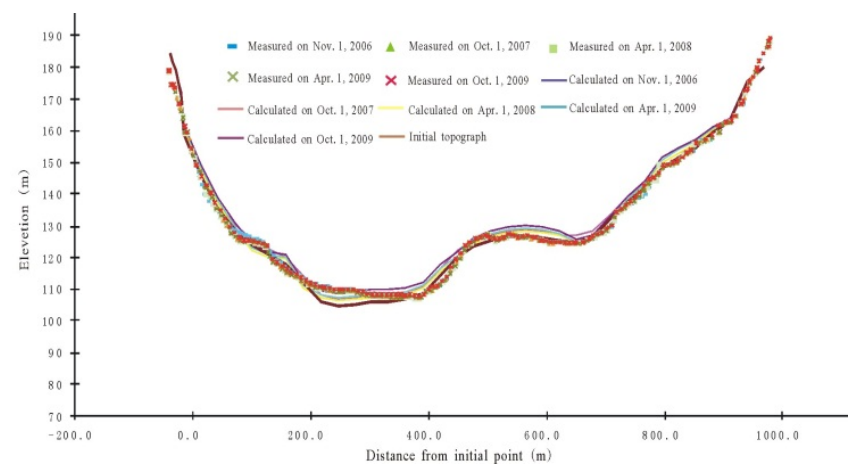

Fig. 2. Comparison of the thickness of erosion-sedimentation at Section 1.

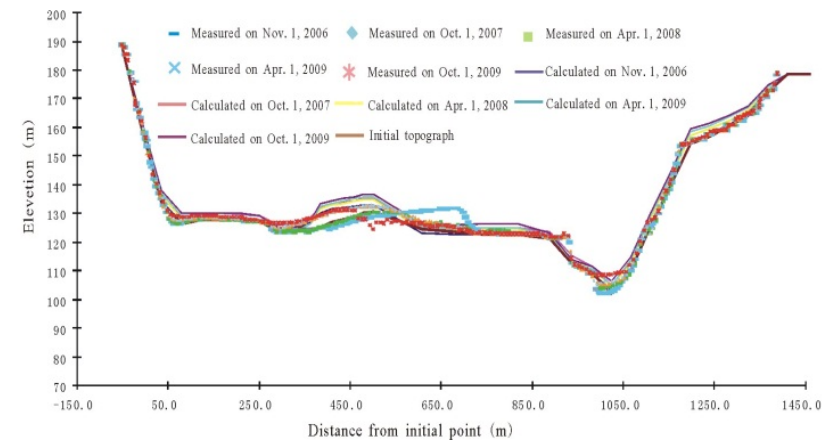

Fig. 3. Comparison of the thickness of erosion-sedimentation at Section 2.

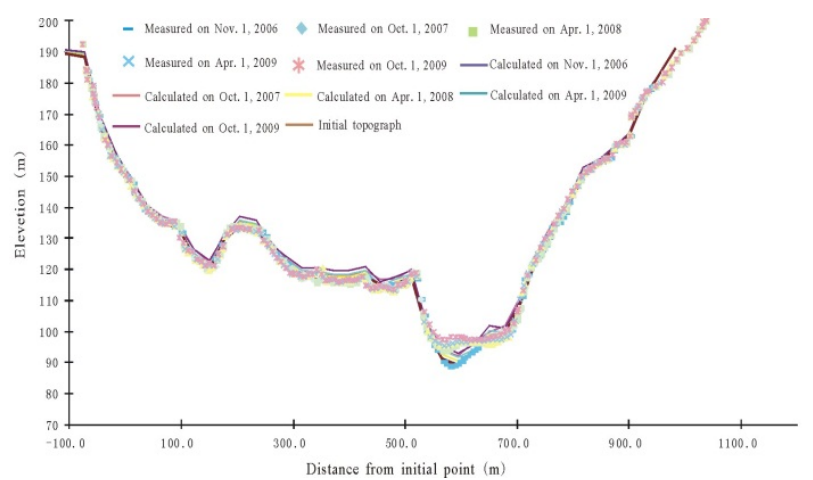

Fig. 4. Comparison of the thickness of erosion-sedimentation at Section 3.

\section{MODEL APPLICATION}

\section{A. Scenario Description}

The model used in this study aims at calculating the thickness of erosion-sedimentation in the next 70 year under the influence of water control project. The time series of flow discharge and sediment concentration by Zhutuo hydrological station are used as the input conditions in the study (Fig. 5). In the figure the discharge is a long series (ten-year) of natural hydrology processed between 1961 and 1970. At the same time, from the River discharge and sediment concentration data, it would seem that the sediment concentration in river between 1961 and 1970 is quite large. The measured river topographic in 2006 is used for simulation.

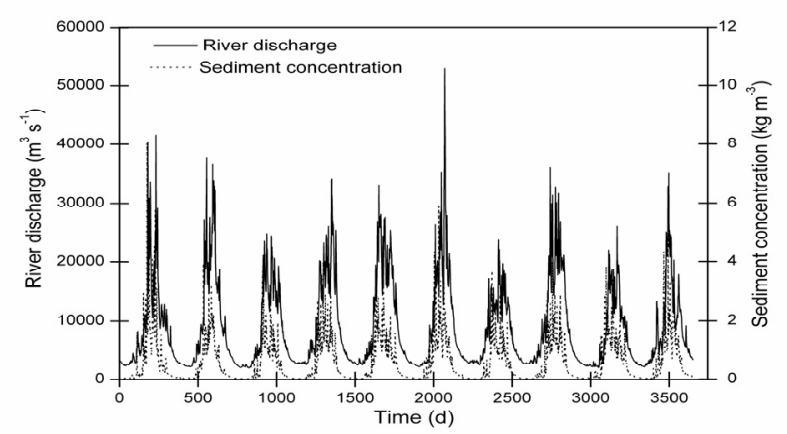

Fig. 5. River discharge and sediment concentration between 2001 and 2010.

\section{B. Results and Discussion}

The upper reservoirs play an important role to block the role and make the rate of deposition reduce, so the trend of deposition becomes slow as time goes on (see Fig. 6). Fig. 6(a) shows the prediction of micro deposition trend in the simulative reach for the 10th year. There is a slight silting in the left of upstream of the simulative reach. In the middle 
tortuous reach, the number of erosion-sedimentation belt is more than the upstream reach, because of the topographic factor. And some deposition also exists in the downstream reach. Fig. 6(b) presents the predicted deposition of sediment for the 30th year. The simulation results show that the range of erosion-sedimentation is larger than the 10th year, and the scope of deposition in the middle reach has the relatively large change. The erosion-sedimentation plumes at the 50th year are showed in Fig. 6(c). For this time, the simulation results show that the thickness of erosion-sedimentation plumes have increased significantly compared with the situation of the 30th year. Meanwhile, the range of erosion-sedimentation belt in the middle reach has greatly expended. Fig. 6(d) shows the prediction of erosion-sedimentation thickness for the 70th year. At this time, the map shows that the deposition trend at the 70th year is more obvious than that of the 50th year, embodied in the elongation of river deposition scope and the increase of river deposition thickness.

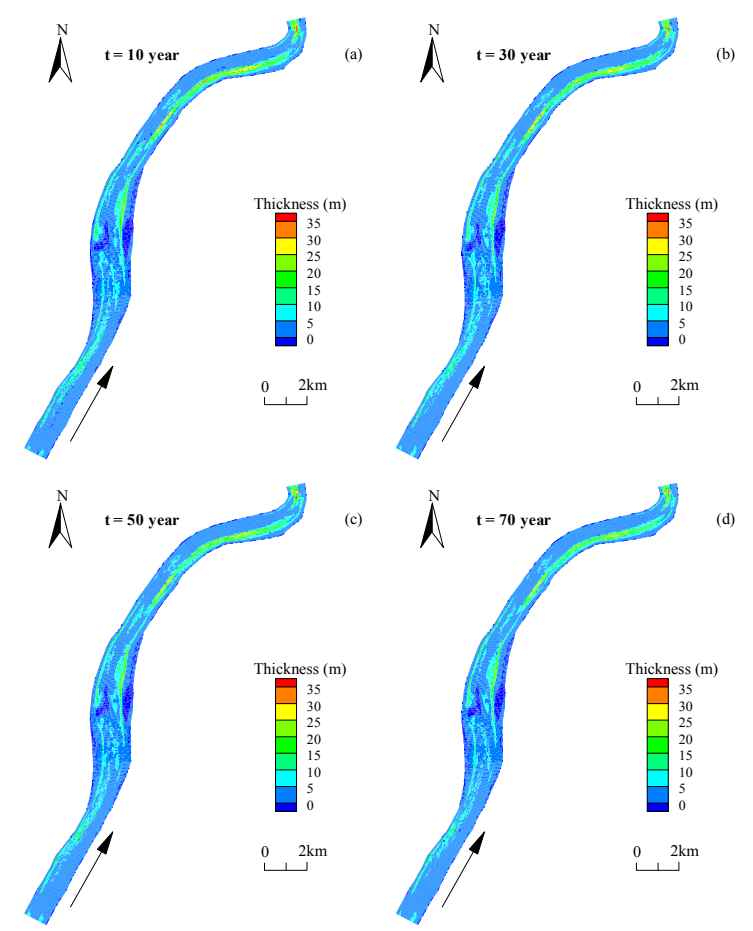

Fig. 6. The thickness of erosion-sedimentation on the 10th, 30th, 50th, 70th year.

\section{CONCLUSION}

The erosion and deposition of the sediment is one of the focus questions in the Three Gorges region. Therefore, the assessment of the sediment deposition thickness requires a model to simulate hydrodynamic, sedimentological and bed deformation processes. In the research, a 2D model, which was based on the combination of the hydrodynamic sub model, the sedimentological model and the bed deformation sub model, was developed to simulate the erosion and deposition process of sediment. A series of simulation results were compared with field measurements on November 1, 2006, October 1, 2007, April 1, 2008, April 1, 2009 and October 1, 2009, and it is shown that the model is applicable to the sediment transport in the river. Then the model is used to calculate the thickness of erosion-sedimentation in the next 70 year in Fengdu of Three Gorges Reservoir. The simulation results can reflect the detailed changes of sediment deposition thickness in the next 70 year. The model developed in this study can be regarded as a basic tool for assessing the sediment transport process in the natural river system, and the research also can provide technical support for the project construction and support the Three Gorges cascaded hydropower scheduling.

\section{REFERENCES}

[1] S. J. Chen, Y. X. Yan, and Y. K. Li, "Spatial and temporal variations of suspended sediment deposition in the alluvial reach of the upper Yellow River from 1952 to 2007," Catena, vol. 92, pp. 30-37, 2012.

[2] J. L. Wellmeyer, M. C. Slattery, and J. D. Phillips, "Quantifying downstream impacts of impoundment on flow regime and channel planform, lower Trinity River, Texas," Geomorphology, vol. 69, pp.1-13, 2005.

[3] S. L. Yang, J. D. Milliman, P. Li, and K. Xu, "50,000 dams later: Erosion of the Yangtze River and its delta," Global and Planetary Change, vol. 75, pp.14-20, 2011.

[4] K. H. Xu and J. D. Milliman, "Seasonal variations of sediment discharge from the Yangtze River before and after impoundment of the Three Gorges Dam," Geomorphology, vol. 104, pp. 276-283, 2009.

[5] Z. Xue, J. P. Liu, and Q. Ge, "Changes in hydrology and sediment delivery of the Mekong River in the last 50 years: connection to damming, monsoon, and ENSO," Earth Surface Processes and Landforms, vol. 36, pp.296-308, 2011.

[6] Z. Xue, R. Y. He, J. P. Liu, and J. C. Warner, "Modeling transport and deposition of the Mekong River sediment," Continental Shelf Research, vol. 37, pp. 66-78, 2012.

[7] K. H. Xu, J. D. Milliman, Z. S. Yang, and H. J. Wang, "Yangtze sediment decline partly from Three Gorges Dam," EOS Transactions, vol. 87, no. 19, pp. 185-190,2006.

[8] M. Dufresne, B. J. Dewals, S. Erpicum, P. Archarmbeau, and M. Pirotton, "Experimental investigation of flow pattern and sediment deposition in rectangular shallow reservoirs," International Journal of Sediment Research, vol. 25, pp. 258-270, 2010.

[9] A. Papanicolaou, A. Bdour, and E. Wicklein, "A numerical model for the study of sediment transport in steep mountain streams," Hydraulic Reserch, vol. 42, no. 4, pp.357-366, 2004.

[10] G. Simpson and S. Castelltort, "Coupled model of surface water flow, sediment transport and morphological evolution," Computers \& Geosciences, vol. 32, no. 10, pp. 1600-1614, 2006.

[11] Z. H. Chen, and H. W. Fang, "Numerical simulation of wind-induced motion in suspended sediment transport," Journal of Hydrodynamics, vol. 19, no. 6, pp.698-704, 2007.

[12] W. S. Zhang, Y. X. Zhao, Y. H. Xu, Y. G. Wang, H. Peng, and G. H. $\mathrm{Xu}$, "2-D numerical simulation of radionuclide transport in the lower Yangtze River," Journal of Hydrodynamics, vol. 24, no. 5, pp. 702-710, 2012.

[13] T. Kiss, K. Fiala, and G. Sipos, "Alterations of channel parameters in response to river regulation works since 1840 on the Lower Tisza River (Hungary)," Geomorphology, vol. 98, pp. 96-110, 2008.

[14] A. E. Draut, J. B. Logan, and M. C. Mastin, "Channel evolution on the dammed Elwha River, Washington, USA," Geomorphology, vol. 127, no. 1-2, pp. 71-87, 2011.

[15] Y. T. Li, "Size distribution of bed materials under the condition of equilibrium transport state," Journal of Sediment Research, vol. 1, pp. $81-87,1987$.

[16] H. Peng, Y. X. Zhao, and P. Cui, "Two-dimensional numerical model for debris flows in Jiangjia Gully, Yunnan Province," Journal of Mountain Science, vol. 8, no. 6, pp. 757-766, 2011.

[17] W. S. Zhang, "Three-dimensional mathematical of suspended sediment in the unsteady surface flow and nonlinear evolution model of shallow wave in the two-layer fluid," Postdoctoral Research Report, Wuhan University of Hydraulic and Electric Engineering, Wuhan, China, 1999.

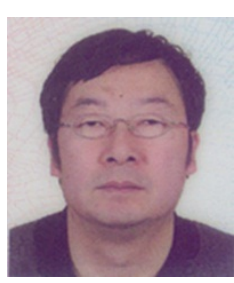

Wanshun Zhang was born in Qingyang of Gansu Province in China in November 1965.At present, he is one of the Professors in the School of Resource and Environmental Science of Wuhan University, Wuhan, P.R. China. Pro. Zhang has over 20 years' experience as a scientist specializing in river flood control, rehabilitation engineering and water quality numerical model, and already published nearly 40 influential papers. He has directed numerous projects in the field of water conservation project and water environmental 
engineering, with primary experience in the area of modeling studies for river rehabilitation modeling, sediment transportation and bed erosion-deposition dynamics, flood control and storm water management strategies, the basin-wide ecological impact survey and analysis of the water conservation and hydropower project, as well as pollution transportation (including conventional pollutant, chemical and heavy metals) in natural water systems.

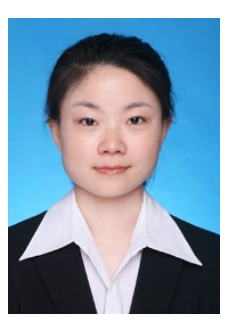

Yanhong Xu is from Xuchang of Henan Province in China and born in May 1987. Xu got her undergraduate degree from geographical information science specialty of Yunnan University in July 2009. On September of the same year, she gained admission into School of Resource and Environmental Sciences of Wuhan University in China to study environmental science, and held the Master of Science degree in environmental science in June 2011. Xu has started the doctoral study in the field of environmental science in School of Resource and Environmental Sciences of Wuhan University since September 2011. Her research direction is the water environmental management. She has already published six papers.

Yanru Wang was born in Jingzhou of Hubei Province in China in February 1991. Wang Yanru was an undergraduate majored in resources and environment \& urban-rural planning management from September 2007 to June 2011 at School of Resource and Environmental Sciences, Wuhan University, Wuhan, China. Wang Yanru was a master's graduate student majored in physical geography since September 2011 at School of Resource and Environmental Sciences, Wuhan University, Wuhan, China.

She has published two papers: one is Study on the total pollutant load allocation method in Taihu Lake Basin (Beijing, China: Journal of China Institute of Water Resources and Hydropower Research, 2011), the other is Planning and effect evaluation for vegetative filter strips in water source area based on model simulation (Washington, DC, United States: IEEE Computer Society, 2012).She is interested in water environment prediction and protection

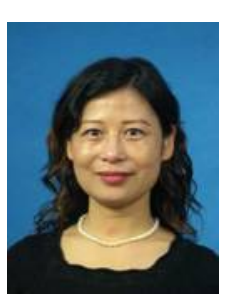

Hong Peng was born in Mianyang of Sichuan Province in China in September 1966, who achieved the Bachelor degree on Biology Science, the Master degree on Macromolecular Material and the Ph.D on Hydrology and Water Resource Sceince in 1990, 1997, 2006, respectively. She is the Professor in the School of Water Resources and Hydropower Engineering of Wuhan University, Wuhan, China. She has over 15 years' experience specializing in water quality protection, water resource management, non-point source pollution control and water environmental management system. She has directed or participated in numerous projects in the fields of water pollution control and water environmental engineering, with primary experience in the area of modeling of water pollution transport in river systems. She has already published more than 20 papers, such as "Adsorption of norfloxacin onto titanium oxide: Effect of drug carrier and dissolved humic acid", "Modeling the biomanipulation in eutrophic shallow lakes", and so on. 